\title{
GERENCIAMENTO DOS PROCESSOS DE NEGÓCIO: UMA ANÁLISE DOS MODELOS DE CICLO DE VIDA BPM
}

\author{
BUSINESS PROCESS MANAGEMENT: \\ ANALYSIS OF BPM LIFECYCLE MODELS
}

\author{
Maria Clara da Cunha Bezerra* E-mail: mariaclarabezerraa@hotmail.com \\ Maryana Scoralick de Almeida Tavares* E-mail: maryanaa@gmail.com \\ Ricardo Moreira da Silva* E-mail: ricardomoreira0203@hotmail.com \\ *Universidade Federal da Paraíba (UFPB), João Pessoa, PB
}

Resumo: A gestão por processos representa um instrumento de melhoria de desempenho das instituições de negócios, porém muitas empresas ainda não se encontram orientadas para os processos. Neste contexto, insere-se a abordagem de gerenciamento dos processos de negócio (business process management ou BPM), que envolve um ciclo feedback sem fim para assegurar que os processos de negócio estejam alinhados com a estratégia organizacional e o foco do cliente. A literatura propõe vários modelos para orientar as organizações à gestão por processos. O objetivo deste trabalho foi analisar modelos de BPM propostos nos últimos 10 anos, a partir de uma síntese descritiva destes, comparação de suas fases, levantando suas convergências e variações, como também a partir do alinhamento desses modelos com atributos chaves ao BPM, que foram identificados a partir da literatura. A contribuição deste trabalho se dá pela utilidade destas análises para pesquisadores ao buscarem estudar sobre diferentes modelos de gerenciamento de processos. Bem como este trabalho também apresenta contribuição prática pois pode ajudar profissionais a adotar modelos e promover o BPM.

Palavras-chave: Business Process Management. Ciclo de vida BPM. Processos de negócio.

Abstract: Process management represents an instrument to improve the performance of business institutions, but many companies, are not yet process oriented. In this context, the business process management (BPM) approach, which involves an endless feedback cycle, is inserted to ensure that business processes are aligned with the organizational strategy and customer focus. The literature proposes several models to guide organizations to process management. The objective of this work was to analyze BPM models proposed in the last 10 years, from a descriptive synthesis of these, comparing their phases, raising their convergences and variations, as well as from the alignment of these models with key BPM attributes that were identified from the literature. The contribution of this work is due to the usefulness of these analyzes for researchers when looking to study different models of process management. As well as this work also presents practical contribution as it can help professionals adopt models and promote BPM.

Keywords: Business Process Management. BPM lifecycle. Business processes.

\section{INTRODUÇÃo}

As organizações estão vivenciando um cenário de crescente competitividade e dinamismo ambiental. Oliveira (2013) argumenta que o mercado globalizado e competitivo não permite que as empresas estejam estruturadas com vários níveis 
hierárquicos e ineficientes. Neste sentindo, insere-se a abordagem de gerenciamento dos processos de negócio, business process management (BPM), que é uma metodologia com o objetivo de aumentar a eficiência e a eficácia dos processos organizacionais através da melhoria em processos e inovação (SCHMIEDEL; VOM BROCKE; RECKER, 2014). Assim como a eliminação de desperdício e agregação de valor nos processos (TEGNER et al., 2016). E impacta diretamente na validação da estratégia organizacional e criação de valor para uma empresa (ENSSLIN et al., 2017). Uma vez que, melhorando continuamente os processos fundamentais adicionam valor para clientes assim como satisfazem outros objetivos estratégicos (TRKMAN, 2010).

Neste contexto, surgem os ciclos de vida do BPM, que devem orientar as empresas em suas ações, ser estruturado para permitir uma compreensão holística em vez de iniciativas isoladas para melhorar os processos (BOER; MÜLLER; CATEN, 2015). Na literatura são encontrados diversos modelos de gerenciamento de processos, estes podem conter uma abordagem tradicional ou abordagem ágil. Estes estudos teóricos e empíricos apresentam diferenças em relação ao número de etapas e atividades que devem ser realizadas para promover BPM (MORAIS et al., 2014).

Diante do exposto, este trabalho se propôs a investigar e selecionar modelos tradicionais de BPM desenvolvidos nos últimos 10 anos no âmbito acadêmicocientífico, fazer uma síntese descritiva dos mesmos e uma análise comparativa entre eles, levantando as convergências e variações de suas fases, bem como as particularidades de cada um.

O trabalho de Morais et al. (2014) dentre os encontrados, foi o que mais se aproximou do que se pretendeu fazer, o mesmo analisou modelos de ciclo de vida BPM, e desenvolveu seu próprio modelo. Porém usou como referência para as comparações o modelo da ABPMP. Este trabalho não utiliza como referência o modelo da ABPMP, e sim, analisa modelos BPM a partir de atributos embasados na literatura que devem estar alinhados aos modelos para que se obtenha sucesso em suas iniciativas, e então analisa criticamente os modelos selecionados quanto ao alinhamento com esses atributos. Ademais, inclui na análise o modelo de Morais et al. (2014) e outros modelos além dos que foram estudados no trabalho de Morais et al. (2014), tornando-se assim um avanço na literatura pesquisada. 


\section{PROCESSOS DE NEGÓCIO E O BPM}

Historicamente, disseminaram-se nas organizações as estruturas verticais com funções e departamentos isolados que operavam independentemente umas das outras (PAIM et al., 2009; DE SORDI, 2008). Essa visão funcional e fragmentada fez prevalecer a especialização e o trabalho individual, separando o trabalho em funções, e perdendo a visão de todo, levando as empresas a se afastarem de seus objetivos de negócios (DE SORDI, 2008).

Neste contexto começam a surgir as empresas orientadas aos processos, que estruturam sua gestão no conceito de processos de negócio, que são fluxos de atividades de diferentes áreas funcionais. Segundo Baldam (2008), a visão por processo procura entender o que precisa ser feito e como fazê-lo, tendo em mente as atividades que agregarão valor para a organização sem se preocupar inicialmente em saber qual o departamento que as executará. Valle e Oliveira (2013) argumentam que a visão por processos não elimina totalmente a visão funcional, no entanto esta mudou de papel, visto que as funções devem agora apoiar os processos.

Diversas abordagens sobre melhoria de desempenho de processos fundiramse gradativamente, dando origem ao business process management (BPM), que consiste em um sistema integrado de gestão do desempenho de negócios voltado para a gestão de processos ponta a ponta. (BROCKE; ROSEMAN, 2013). O BPM é definido por Trkman (2010) como todos os esforços em uma organização para analisar e melhorar continuamente atividades de uma empresa.

Apesar de haver diferentes modelos para a implantação do gerenciamento de processos, eles têm em comum a forma cíclica, por esta razão, fala-se em "ciclos de BPM". Um modelo sistêmico composto por eventos, atividades e tarefas, com objetivo de organizar o fluxo e as operações de troca de valores entre fornecedores e clientes deve orientar o BPM (KLUSKA; LIMA; COSTA, 2015).

Para Mccormack et al. (2009) alcançando maior maturidade no BPM, a organização terá maior controle sobre os resultados, melhor projeção de metas, custos e desempenho, ganhar mais eficiência para alcançar objetivos definidos e melhorar a gestão da capacidade de propor inovações.

Além dos modelos tradicionais de BPM, dentre os quais estão os modelos analisados neste trabalho, autores também começaram a desenvolver modelos ágeis 
para o gerenciamento de processos, que pudessem ser mais flexíveis e adaptáveis a ambientes dinâmicos e rápidas mudanças (MARTINS; ZACARIAS, 2017; BURMEISTER et al., 2006; BIDER; BELLINGER; PERJONS, 2011; BIDER; JALALI, 2016).

A definição de processos de negócios ágeis diz respeito à capacidade de descobrir mudanças e oportunidades e reagir adequadamente e rapidamente às mesmas (MARTINS; ZACARIAS, 2017; BIDER; BELLINGER; PERJONS, 2011; BIDER; JALALI, 2016). Burmeister et al. (2006), por exemplo, desenvolveu uma abordagem de processos ágeis que poderia apoiar processos complexos, diminuir os esforços para alterar os processos e permitir maior flexibilidade não apenas na modelagem, mas também na execução de processos através de sistemas de software. Thiemich e puhlmann (2013) argumentam que abordagens ágeis reduzem a sobrecarga de uma fase de análise e projeto de vários meses e fornecem resultados visíveis nas fases iniciais do projeto.

Martins e Zacarias (2017) argumentam que os modelos tradicionais seguem uma sequência rigorosa de criar os modelos de forma detalhada e implementar na organização. E estes podem não ser adequados, por exemplo, em organizações com alto grau de mudanças (MARTINS; ZACARIAS, 2017; BIDER; BELLINGER; PERJONS, 2011). Todavia é importante destacar que existem vantagens e desvantagens tanto nos modelos tradicionais como nos modelos ágeis.

Martins e Zacarias (2017) consideram que as equipes devem levar em conta a dimensão da organização e a complexidade dos processos de negócios. Para grandes empresas o autor propõe uma etapa inicial que inclui uma descrição de todos os processos organizacionais, logo uma abordagem ágil não é aconselhável e a tradicional deve ser aplicada. Para Bider e Jalali (2016) as vantagens da metodologia ágil cabem minimizar o risco do processo e do sistema que ele suporta não se adequar à realidade do negócio. No entanto nos modelos ágeis existe a possibilidade limitada de usar métodos formais para otimização de processos, o que pode ser superado utilizando-se a metodologia tradicional. Logo se faz importante entender a realidade da empresa e dos seus processos e definir qual das abordagens (tradicionais ou ágeis) melhor se adequam. 


\section{METODOLOGIA}

O processo metodológico deste estudo compreende 6 etapas, como é apresentado na figura 1 e a seguir serão descritas cada uma destas.

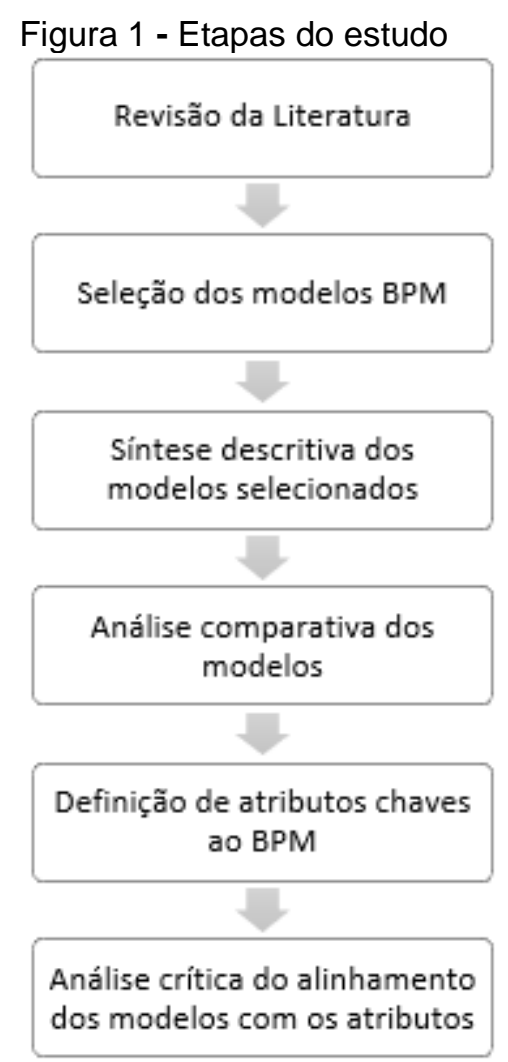

Fonte: Elaborado pelos autores (2017)

Para a condução da revisão da literatura foi utilizada a base dados Web of Science, o Google Acadêmico, como também foram selecionados trabalhos a partir das referências daqueles já encontrados, obtendo-se assim, um portfólio de trabalhos na forma de artigos, teses, dissertações, como também livros, nos quais o número de citações confirmava sua relevância nessa área de estudo.

No Web of Science foi realizada uma busca direcionada aos modelos BPM, utilizando-se os termos de busca "BPM" e "business process management" em combinação com os termos "model" e "lifecycle", tendo como resultado 137 artigos. Porém grande parte destes artigos não contemplavam modelos BPM, então após a leitura de títulos e resumos, este número caiu para 23 artigos que foram adicionados ao portfólio por comentarem sobre modelos, todavia, nesse primeiro momento apenas 
dois trabalhos eram dedicados a descrever um modelo BPM, bem como descrever suas etapas, então esses foram selecionados para serem analisados a posteriori. Então buscou-se o Google Acadêmico, para selecionar outros trabalhos para o portfólio, onde foram utilizadas as palavras chaves "modelos de ciclo de vida BPM" e "gerenciamento de processos de negócio" e por fim foram também analisados trabalhos nos quais foram desenvolvidos modelos BPM a partir das referências dos trabalhos selecionados até o momento.

No Google Acadêmico foram encontrados diversos modelos para orientar a gestão por processos de negócio. A segunda etapa metodológica que consistiu na seleção dos modelos para análise foi feita de acordo com critério temporal, logo os mais recentes que foram encontrados na revisão da literatura foram analisados, bem como aqueles que foram citados pelo maior número de trabalhos encontrados. $\mathrm{O}$ Quadro 1 apresenta na primeira coluna os trabalhos dos últimos 10 anos que desenvolveram modelos de ciclo BPM e foram então selecionados para este estudo, que foram eles: Modelo de Baldam (2008), Modelo da ABPMP (2009), Modelo de Dumas et al. (2013), Modelo de Scheer e Brabänder (2013), Modelo de Morais et al. (2014) e Modelo de Bernardo, Galina e Pádua (2017). E na segunda coluna estão apresentados os artigos e dissertações nos que estes modelos foram utilizados. Observa-se que o Modelo de Bernardo, Galina e Pádua (2017), por ser recente, não foi utilizado em outros trabalhos acadêmicos até a presente data.

Quadro 1 - Modelos selecionados para a análise e sua ocorrência na literatura

\begin{tabular}{|l|l|}
\hline \multicolumn{1}{|c|}{ MODELO } & \multicolumn{1}{c|}{ OCORRËNCIAS } \\
\hline Baldam (2008) & $\begin{array}{l}\text { Gorte (2016); Kluska (2015); Mariano e Muller (2012); } \\
\text { Tessari (2008) }\end{array}$ \\
\hline ABPMP (2009) & Bernardo, Galina e Pádua (2017); Morais (2014) \\
\hline Dumas et al. (2013) & Haddad et al. (2016) \\
\hline Scheer \& Brabänder (2013) & Boer (2014); Sousa (2015) \\
\hline Morais et al. (2014) & Bernardo, Galina e Pádua (2017); Garcia (2015) \\
\hline Bernardo, Galina e Pádua (2017) & \multicolumn{1}{c|}{-} \\
\hline
\end{tabular}

Fonte: Elaborado pelos autores (2017)

Uma vez selecionados os modelos, partiu-se para terceira etapa que consistiu na síntese descritiva dos modelos. E então foi feita uma análise comparativa dos mesmos, que é definido como quarta etapa, onde foi identificada as fases dos modelos 
e as definições e características delas, o que resultou em um quadro que apresenta as convergências e divergências entre essas fases.

A quinta etapa consistiu em definir, a partir da literatura pesquisada, atributos que são chaves às iniciativas e sucesso BPM, procurou-se selecionar atributos bem embasados na literatura e defendidos por diferentes autores. E por fim a quinta fase consistiu na análise crítica do alinhamento dos modelos com os atributos, onde foi avaliado o grau de presença desses atributos em cada um dos modelos, a partir da descrição contida no material de cada modelo.

\section{SÍNTESE DESCRITIVA DOS MODELOS}

\section{a) Modelo de Baldam (2008)}

Baldam (2008) divide o ciclo BPM em quatro etapas, apresentadas na Figura 2. O Planejamento tem o propósito de definir as atividades de BPM que contribuirão para o alcance das metas organizacionais, através do entendimento do ambiente externo e interno. Também engloba a estratégia organizacional, fazendo a definição de estratégias, objetivos e abordagens para promover mudanças. Realiza a seleção das ferramentas e técnicas de apoio ao BPM, a preparação da visão global de processos, definição de planos de ação, seleção e priorização dos processos, estimação de custos e prazos e diretrizes. Por fim, formam-se as equipes de trabalhos para processos específicos.

Para a seleção e priorização dos processos, é necessário verificar os pontos fracos dos processos que causam danos à organização, definir quais são os processos-chave para a estratégia e identificar oportunidades de negócio.

A fase de Modelagem e otimização de processos trata da atividade de "construir" modelos. Segundo Baldam (2008), essa é a fase mais visível do BPM. O autor subdivide a modelagem em duas atividades: Modelagem "As Is", e Otimização e modelagem "To Be".

Para conseguir otimizar um processo é necessário entender sua situação atual, para isto, deve-se modelar os processos no seu estado inicial ("As Is"). Há interações entre os envolvidos, como atividades de colaboração e reuniões, e devem ser usadas técnicas como entrevistas e brainstorming. Em seguida, realiza-se a otimização e 
modelagem na situação futura, "To Be" que consiste em empregar metodologias como simulações, inovações e redesenho, visando otimizar e inovar os processos.

$\mathrm{Na}$ fase de Execução de processos, são postas em prática as definições da fase de modelagem e otimização do processo. Algumas atividades que garantem a implantação da execução de processos são a coordenação e ajustes dos equipamentos e softwares, coordenação de testes, definição planos de transferência de tecnologia, treinamentos, métodos, transferência da monitoria e controle da execução do processo aos executores do mesmo, realização das mudanças de curto prazo e estabelecimento de critérios de fornecimento de dados para controle e análise dos processos.

Figura 2- Ciclo de BPM segundo Baldam

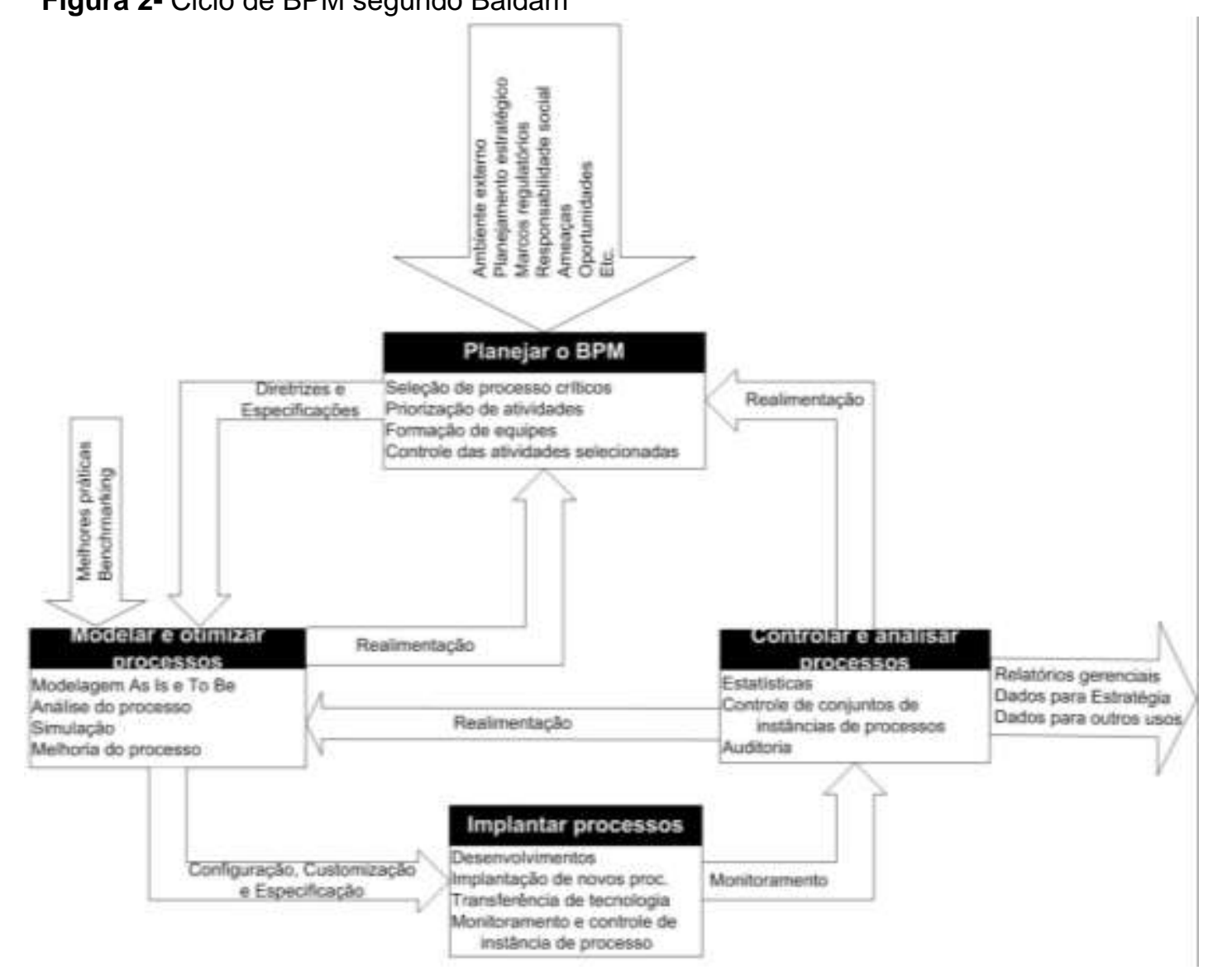

Fonte: Baldam (2008)

Esta etapa é crítica e decisiva, pois o projeto do processo passará às mãos dos usuários de fato e serão percebidos os efeitos da gestão de mudança, com todos seus 
impactos positivos e negativos. Aqui, as competências subjetivas e sociais dos responsáveis pela implantação farão diferença.

Por fim, a fase de Controle e análise de dados é responsável por fornecer informações sobre o comportamento, adequação e conformidade dos processos; caso contrário, faz-se os ajustes necessários nos processos, nas metas ou mesmo na estratégia da organização. Para isso são utilizados indicadores, métodos estatísticos e diagramas de causa e efeito, gerando informações que posteriormente irão realimentar as atividades de otimização e planejamento.

\section{b) Modelo da ABPMP (2009)}

O modelo proposto pela Association of Business Process Management Professional (ABPMP) engloba seis fases, que são apresentadas na Figura 3.

$\mathrm{Na}$ fase de planejamento e estratégia deve-se desenvolver um plano e uma estratégia dirigida a processos para a organização. O plano deve ser focado na gestão contínua de processos centrados no cliente, além de estabelecer a base para o alinhamento com a estratégia organizacional e a integração de pessoas, processos e sistemas ao longo dos limites funcionais. Nessa fase de planejamento, a estratégia e o direcionamento do processo BPM são definidos, são identificados os papéis e responsabilidades organizacionais apropriadas ao BPM, metas, expectativas de desempenho, metodologias e, em alguns casos, há mudanças estratégicas.

A fase seguinte, denominada "Análise de processos de negócio", tem a finalidade de entender os atuais processos organizacionais no contexto das metas e objetivos desejados. A análise é responsável por assimilar "informações oriundas de planos estratégicos, modelos de processo, medições de desempenho, mudanças no ambiente externo e outros fatores" (ABPMP, 2009, p. 37).

A fase de "Desenho e modelagem de processos de negócio" engloba atividades que focam no desenho de como o trabalho ocorre de modo a entregar valor aos clientes. A sequência de atividades é documentada, incluindo o desenho, o tempo, o local e a metodologia do trabalho realizado, além dos atores do processo. Essa fase também é responsável por assegurar que métricas e controles apropriados realizem medições de desempenho e conformidade. 
A fase subsequente é a de "Implementação de processos de negócio", que é definida como a efetiva realização do desenho aprovado, em procedimentos e fluxo de trabalho documentados, testados e operacionais. Ademais, é realizada a implementação de políticas e procedimentos.

De acordo com a ABPMP (2009, p. 38), o monitoramento e controle de processos "proveem informações chave de desempenho de processos através de métricas relacionadas às metas e ao valor para a organização. A análise de informações de desempenho de processos pode resultar em atividades de melhoria, redesenho ou reengenharia".

Figura 3 - Ciclo de BPM segundo a ABPMP

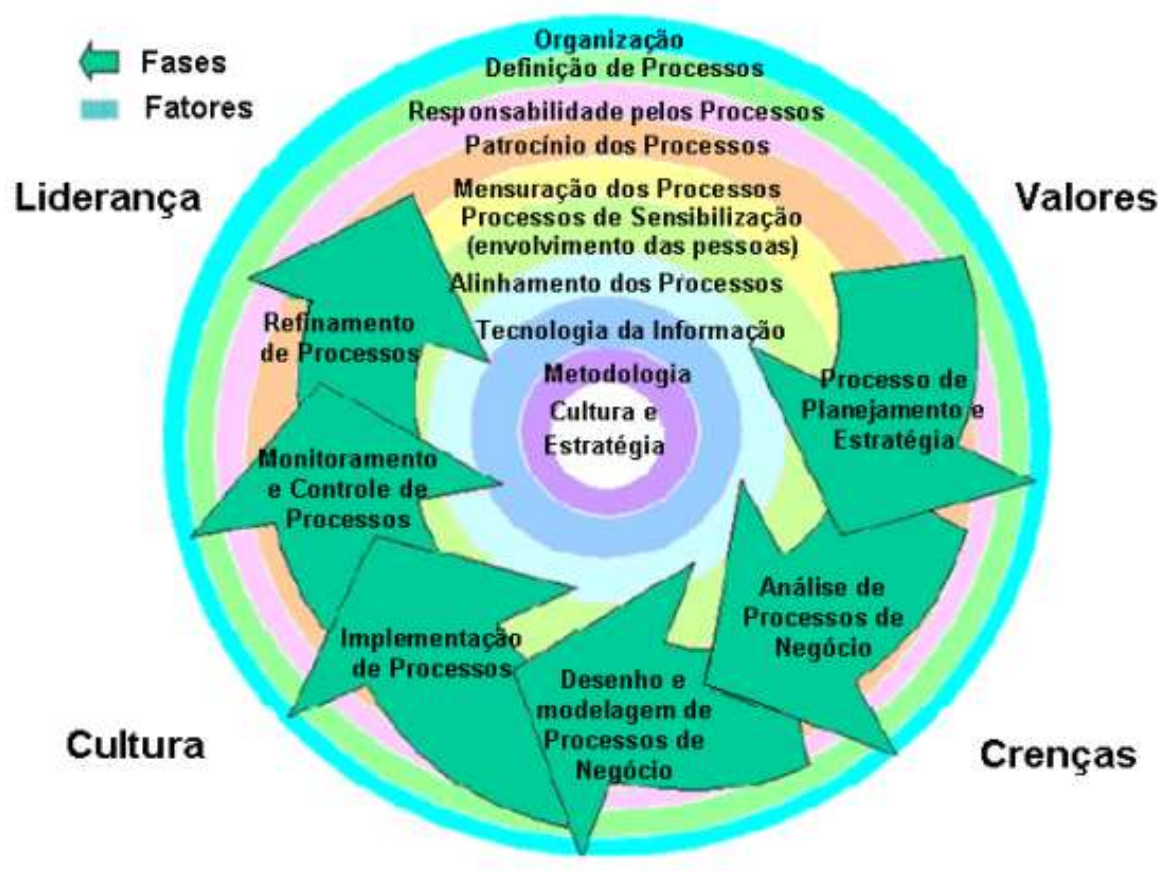

Fonte: ABPMP (2009)

Por fim, o refinamento de processos trata da contínua medição e monitoramento de processos de negócio. Tal atividade fornece a informação necessária para que gestores de processo ajustem os recursos de modo a atingir os objetivos dos processos.

c) Modelo de Dumas et al. (2013)

O modelo desenvolvido por Dumas et al. 2013 é apresentado na figura 4. $\mathrm{Na}$ 
fase de Identificação do processo, um problema de negócio é colocado, os processos relevantes para o problema são identificados, delimitados e relacionados uns com os outros. O resultado da identificação do processo é uma arquitetura de processos nova ou atualizada que fornece uma visão geral dos processos em uma organização e seus relacionamentos. Em alguns casos, a identificação do processo é feita em paralelo com a identificação da medida de desempenho.

O Descobrimento do processo é a documentação do processo atual, tipicamente na forma de um ou vários modelos de processo tal como está ("As Is"). Pode ser realizada através de observações, entrevistas, análise documental, entre outros.

$\mathrm{Na}$ fase de Análise, as questões associadas ao processo "As Is", suas percepções e fraquezas são identificadas, documentadas e, sempre que possível, quantificadas utilizando medidas de desempenho. O resultado desta fase é um conjunto estruturado de questões, que geralmente são priorizadas em termos de seu impacto, e às vezes também em termos do esforço estimado necessário para resolvêlos.

O Redesenho do processo tem o objetivo de identificar mudanças no processo que ajudariam a abordar as questões identificadas na fase anterior e permitir que a organização atinja seus objetivos de desempenho. Para tal, são analisadas e comparadas múltiplas opções de mudança em termos das medidas de desempenho escolhidas. Isso implica que o redesenho do processo e a análise de processo caminhem lado a lado: à medida que novas opções de mudança são propostas, elas são analisadas usando técnicas de análise de processo. Eventualmente, as opções de mudança mais promissoras são combinadas, levando a um processo redesenhado. A saída desta fase é tipicamente um modelo de processo " $T o B e$ ", que serve como base para a próxima fase.

$\mathrm{Na}$ fase de Implementação do processo, são preparadas e executadas as mudanças necessárias para passar do processo de "As Is" para "To Be". A implementação do processo abrange dois aspectos: gerenciamento de mudanças organizacionais e automação de processos. Gestão de mudanças organizacionais refere-se ao conjunto de atividades necessárias, como a exposição de mudanças, planos de ação e treinamentos, para alterar a forma de trabalhar de todos os participantes envolvidos no processo. 
A automação de processos, por outro lado, refere-se ao desenvolvimento e implantação de sistemas de $\mathrm{Tl}$ (ou versões aprimoradas de sistemas de $\mathrm{Tl}$ existentes) que suportam o processo "To Be". O autor ressalta que a tecnologia, e especialmente tecnologia da Informação (TI), é um instrumento fundamental para melhorar os processos de negócios. No entanto, para alcançar a máxima eficácia, os engenheiros de sistemas precisam estar cientes de que a tecnologia é apenas um instrumento para gerenciar e executar processos.

A fase seguinte é a de Monitoramento e Controle. Uma vez que o processo redesenhado está em execução, os dados relevantes são coletados e analisados para determinar quão bem o processo está se comportando em relação às suas medidas de desempenho e objetivos de desempenho. Gargalos, erros recorrentes ou desvios com relação ao comportamento pretendido são identificados e ações corretivas são realizadas.

Figura 4 - Ciclo de BPM segundo Dumas et al.

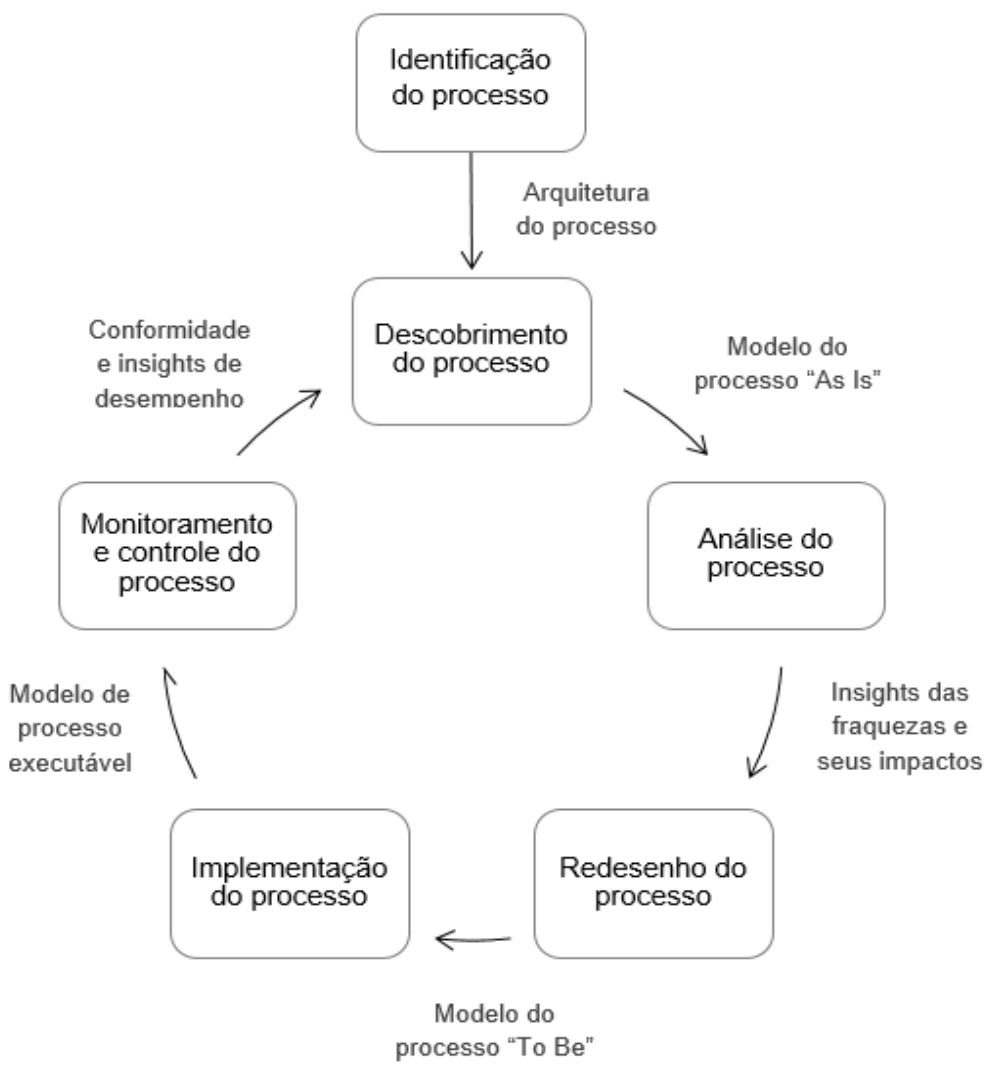

Fonte: Adaptado de Dumas et al. (2013)

Assim, podem então surgir novas questões, no mesmo ou em outros processos, exigindo que o ciclo seja repetido numa base contínua. 


\section{d) Modelo de Scheer e Brabänder (2013)}

De acordo com Scheer e Brabänder (2013), o ciclo de vida de BPM compreende quatro fases, apresentadas na Figura 5. A fase de Estratégia é "o alicerce para alinhar esses processos com a estratégia corporativa geral” (SCHEER; BRABÄNDER, 2013, p. 282). Segundo os autores, é necessário conhecer a estratégia e os objetivos de negócio da empresa para manter alinhados os processos de negócio. Portanto, em toda mudança na estratégia empresarial, os processos de negócio devem ser adaptados.

O objetivo da fase de Desenho é o alinhamento dos processos com as necessidades e exigências do mercado, que compreende desenho, análise e otimização dos processos como parte de um ciclo de melhoria continua, onde se analisa o fluxo de processos atual ("As Is") e o otimiza por meio da criação de um fluxo "To Be" mais eficiente e de melhor qualidade.

$\mathrm{Na}$ fase de Implementação, são feitos processos de transformação e gestão de mudanças para colocar em funcionamento o que foi projetado. Para isso, podem ocorrer mudanças na estrutura organizacional e no sistema de tecnologia da informação ( $\mathrm{TI})$ da empresa, acompanhados de comunicação e treinamentos para apoiar os funcionários afetados pelas mudanças (SCHEER; BRABÄNDER, 2013).

Para realizar o Controle, Scheer e Brabänder (2013) afirmam que se deve mensurar a eficiência dos processos e analisar comparativamente se os indicadores de desempenho definidos estão de acordo com as metas traçadas; assim, pode-se identificar oportunidades para realizar mudanças que fechem o ciclo de otimização de BPM.

O objetivo da fase de Controle é "assegurar que os processos de negócio implementados sejam executados de acordo com o que foi definido durante a fase de desenho e que todas as etapas de controle sejam adequadas e estejam funcionando" (SCHEER; BRABÄNDER, 2013, p. 288). 
Figura 5 - Ciclo de BPM segundo Scheer e Brabänder

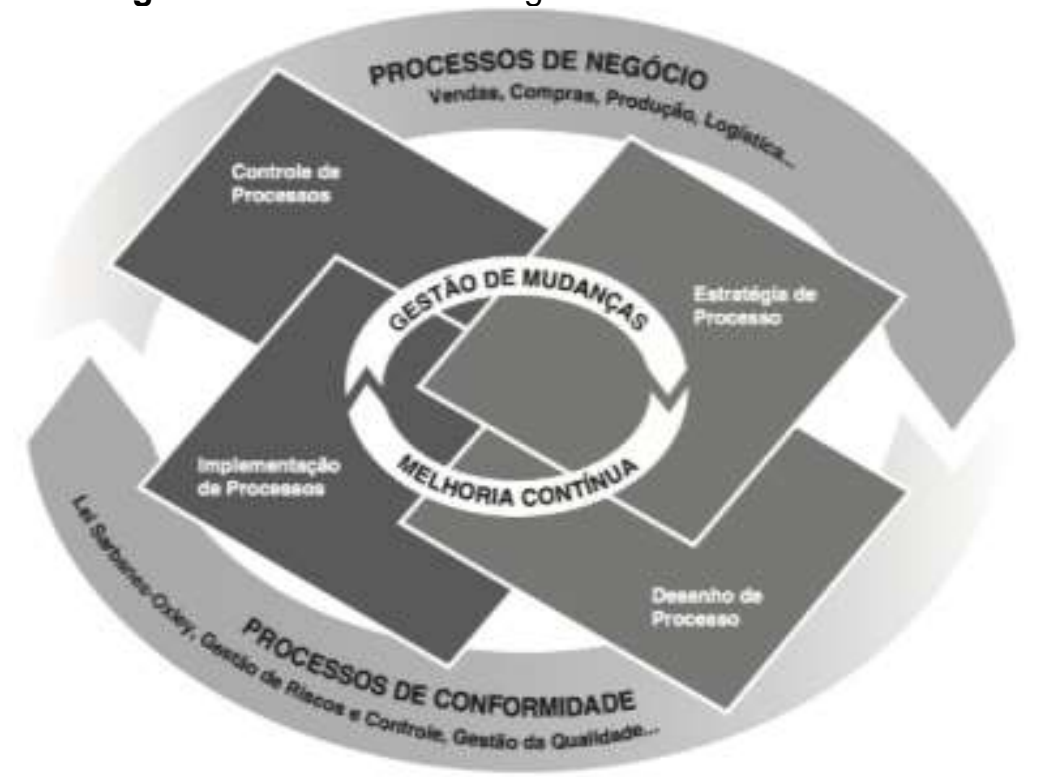

Fonte: Scheer e Brabänder (2013)

\section{e) Modelo de Morais et al. (2014)}

Para desenvolver o seu modelo, que está apresentado na figura 6, Morais et al. (2014) usaram como parâmetro de referência o modelo ABPMP (2009) e incorporaram as práticas de alinhamento estratégico propostas por Burlton (2010 apud Morais et al., 2014). Estas práticas se concentraram na primeira fase do modelo proposto por Morais et al. (2014) e são denominadas de Planejamento e estratégia do processo inicial.

Tais práticas de alinhamento estratégico subdividem-se em nove atividades, as quais estão apresentadas na Figura 6. Essas atividades destinam-se a garantir uma estruturação inicial da arquitetura do processo que, em um processo evolutivo, será revisada.

As próximas fases do modelo são análogas àquelas do modelo ABPMP (2009): Análise, Projeto e modelagem, Implementação, Monitoramento e controle dos negócios e, por fim, Refino e revisão do planejamento, que precede cada nova interação do ciclo projetada no quadro, e analisa as atividades associada com a estratégia para o portfólio de processos de negócios. 
Figura 6 - Ciclo de BPM segundo Morais et al. (2014)

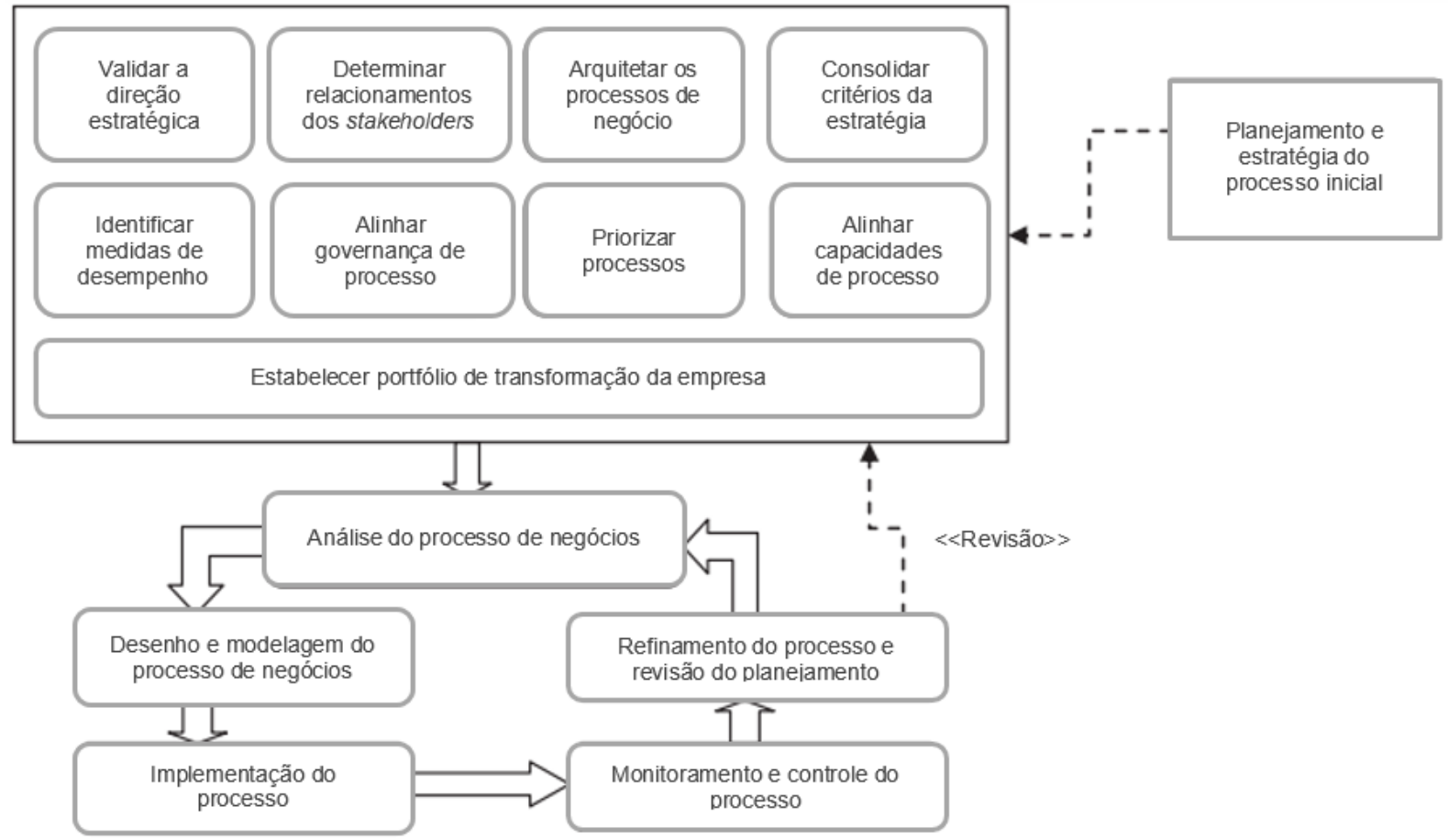

Fonte: Adaptado de Morais et al. (2014)

\section{f) Modelo de Bernardo, Galina e Pádua (2017)}

Este modelo, que está representado na Figura 7, incorpora fatores externos para a organização no ciclo de vida de BPM por meio das capacidades dinâmicas (CDs), por estas facilitarem a adaptação da organização em resposta ao dinamismo do ambiente externo, assim aumentando o desempenho do BPM.

Este modelo teve como base o modelo de Morais et al. (2014), além de incorporar o conceito de meta-capacidades de Teece (2007), que se referem à necessidade de ajustar a orientação da organização para o contexto de mercado. São elas: detecção, apreensão e transformação. Para cada meta-capacidade, Teece (2007) desenvolveu microfundamentos que auxiliam na compreensão da operacionalização das CDs e que contribuem para a mudança organizacional.

A meta-capacidade de detecção é responsável por incorporar os aspectos do ambiente externo à organização e consolidam a primeira fase do modelo proposto e contribuem para o passo seguinte (a apreensão), através da integração da perspectiva externa em planejamento e estratégia organizacional. 
A meta-capacidade de apreensão aproveita os recursos organizacionais para o planejamento de negócios em conformidade com o ambiente externo (detecção) através dos seus microfundamentos. Essas atividades buscam validar o processo inicial de planejamento e estratégia para alinhar capacidades organizacionais com recursos e estabelecer um portfólio de transformação.

Por sua vez, a meta-capacidade de transformação é evidente nas atividades do BPM dos ciclos tradicionais, que são elas: planejamento e estratégia, análise, projeto, implementação, controle e monitoramento e refino. Essas etapas fornecem a base para a renovação contínua através de seus microfundamentos, que contribuem para a descentralização e decomposição, governança e gestão do conhecimento, elementos que estão estreitamente ligadas ao produto resultante do ciclo de vida de BPM.

O Quadro 2 apresenta os microfundamentos que estruturam as metacapacidades dinâmicas e contribuem para as mudanças organizacionais.

Quadro 2 - Microfundamentos referentes às fases de detecção, apreensão e transformação

\begin{tabular}{|l|l|}
\hline Meta-capacidade & \multicolumn{1}{|c|}{ Microfundamentos } \\
\hline Detecção & $\begin{array}{l}\text { (1) Processos para direcionar P\&D internos e selecionar novas tecnologias; } \\
\text { (2) Processos para explorar a inovação de fornecedores e complementares; } \\
\text { (3) Processos para explorar desenvolvimentos exógenos em ciência e } \\
\text { tecnologia; } \\
\text { (4) Processos para identificar os mercados-alvo, as necessidades dos } \\
\text { clientes e as inovações. }\end{array}$ \\
\hline Apreensão & $\begin{array}{l}\text { (1) Delimitação da solução do cliente e do modelo de negócio, incluindo a } \\
\text { seleção de tecnologia e arquitetura de produtos, design de arquitetura de } \\
\text { receita, seleção de clientes-alvo e concepção de mecanismos para captar } \\
\text { valor; } \\
\text { (2) Seleção de protocolos de decisão, que envolve o reconhecimento de } \\
\text { pontos de inflexão e complementaridades; } \\
\text { (3) Seleção de fronteiras empresariais para gerenciar e controlar } \\
\text { plataformas complementares; } \\
\text { (4) Estabelecimento de compromisso, engajamento de liderança, } \\
\text { estabelecimento de comunicação e reconhecimento de fatores, valores e } \\
\text { cultura não-econômicos. }\end{array}$ \\
\hline (1) Descentralização e decomposição para facilitar a adoção de estruturas \\
flexíveis e estratégias de inovação para desenvolver, integrar e coordenar \\
as habilidades; \\
(2) Melhoria da governança, que envolve a realização de alinhamento, \\
minimização de problemas de agência e prevenção da dissipação de \\
receita; \\
(3) Co-especialização, que envolve a gestão estratégica para assegurar que \\
a combinação de recursos melhora a criação de valor; \\
(4) Gestão do conhecimento, que engloba a aprendizagem, transferência de \\
conhecimento, integração de know-how, e proteção da propriedade \\
intelectual.
\end{tabular}

Fonte: Adaptado de Bernardo, Galina e Pádua (2017) 
Figura 7 - Ciclo de BPM segundo Bernardo, Galina e Pádua (2017)

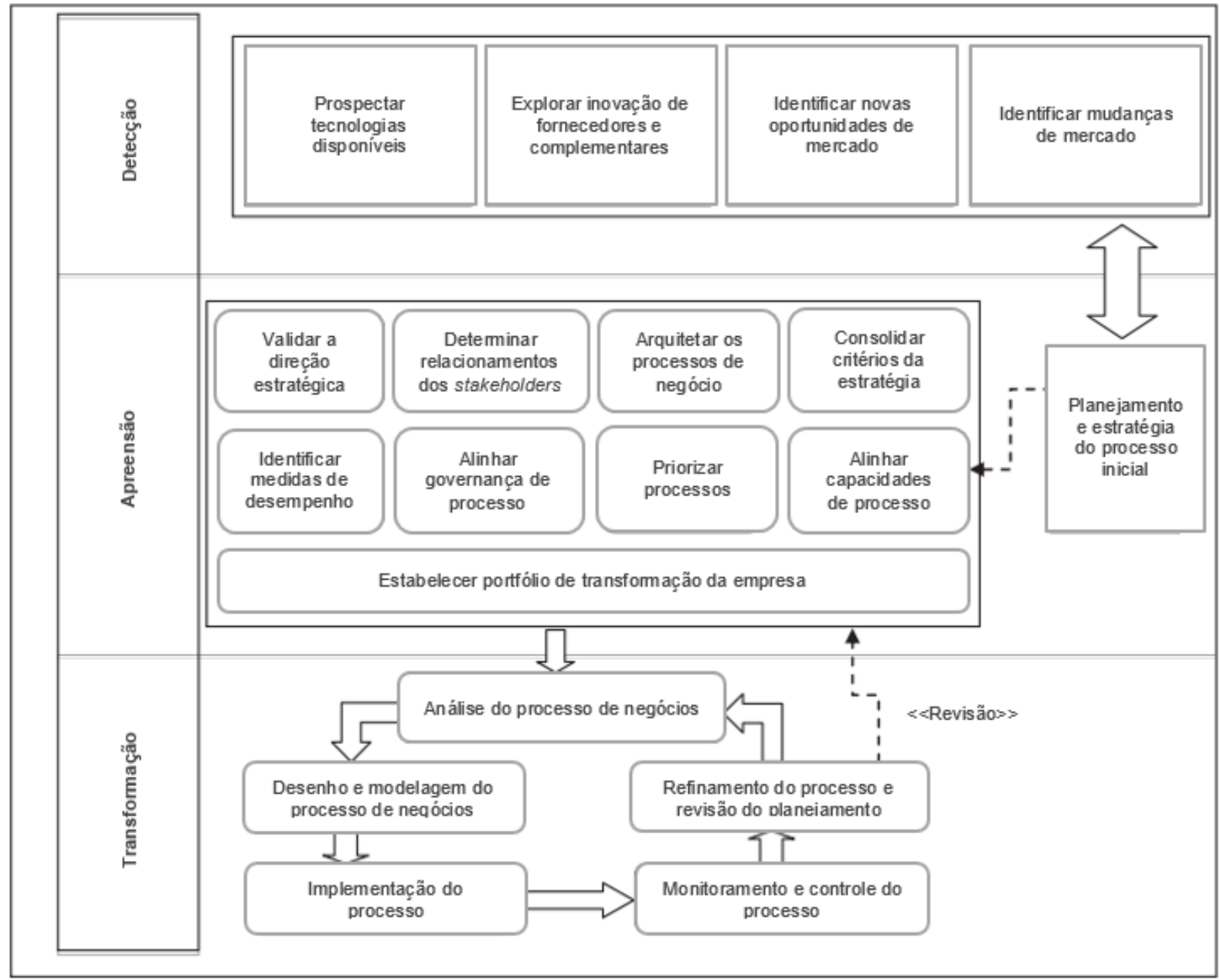

Fonte: Adaptado de Bernardo, Galina e Pádua (2017)

As fases seguintes do modelo também são análogas as do modelo ABPMP (2009): Análise, Projeto e modelagem, Implementação, Monitoramento e controle dos negócios e, por fim, Refino e revisão do planejamento.

\section{ANÁLISE COMPARATIVA DOS MODELOS}

A partir do que foi discutido nos itens anteriores, foi feita uma análise comparativa entre os modelos e suas fases. As principais fases de cada modelo são apresentadas no Quadro 3.

Apesar das diferenças semânticas das fases nos modelos analisados, muitas delas apresentam semelhanças no seu conteúdo e propósito, enquanto outras divergem de um modelo para outro. 
Quadro 3 - Modelos de BPM selecionados e suas fases

\begin{tabular}{|c|l|}
\hline Modelo & \multicolumn{1}{c|}{ Fases } \\
\hline Baldam (2008) & $\begin{array}{l}\text { Planejamento; Modelagem e otimização; Execução; Controle e } \\
\text { análise de dados }\end{array}$ \\
\hline ABPMP (2009) & $\begin{array}{l}\text { Planejamento e estratégia; Análise; Desenho e modelagem; } \\
\text { Implementação; Monitoramento e controle; Refinamento }\end{array}$ \\
\hline Dumas et al. (2013) & $\begin{array}{l}\text { Identificação; Descobrimento; Análise; Redesenho; Implementação; } \\
\text { Monitoramento e controle }\end{array}$ \\
\hline Scheer e Brabänder (2013) & Estratégia; Desenho; Implementação; Controle \\
\hline Morais et al. (2014) & $\begin{array}{l}\text { Planejamento e estratégia; Análise; Desenho e modelagem; } \\
\text { Implementação; Monitoramento e controle; Refinamento e revisão }\end{array}$ \\
\hline Bernardo, Galina e Pádua & $\begin{array}{l}\text { Detecção; Planejamento e estratégia; Análise; Desenho e } \\
\text { modelagem; Implementação; Monitoramento e controle; Refinamento }\end{array}$ \\
\hline
\end{tabular}

Fonte: Elaborado pelos autores (2017)

Os modelos de Baldam (2008), ABPMP (2009), Scheer e Brabänder (2013) e Morais et al. (2014) apresentam um forte grau de semelhança na fase inicial. O modelo Bernardo, Galina e Pádua (2017) apresenta uma primeira fase que incorpora o ambiente externo ao ciclo BPM.

No que concerne o modelo de Dumas et al. (2013), sua primeira fase é definida como "Identificação" e diverge da fase inicial dos outros modelos analisados, pois não trata dos pontos necessários para um efetivo planejamento BPM e para um devido alinhamento da estratégia da organização aos processos de negócio.

Na primeira fase do modelo de Baldam (2008) estão as atividades de BPM que contribuirão para o alcance das metas organizacionais. O modelo da ABPMP (2009) fala da identificação e definição papéis e responsabilidades organizacionais apropriadas ao BPM, metas, expectativas de desempenho, metodologias e mudanças estratégicas. Scheer e Brabänder (2013) consideram que a primeira fase de seu modelo seja o alicerce para alinhar os processos com a estratégia corporativa geral; logo, seria necessário conhecer a estratégia e os objetivos de negócio da empresa para manter alinhados os processos de negócio.

O modelo de Morais et al. (2014) também apresenta essas atividades em sua primeira fase, que é similar à segunda fase do modelo de Bernardo, Galina e Pádua (2017), e alinham a estratégia ao processo de negócio.

Todavia, na primeira fase do modelo de Dumas et al. (2013), é colocado o problema de negócio e são identificados os processos relevantes para o problema, que resulta em uma arquitetura de processos e fornece uma visão geral dos mesmos. Assim, esta encontra-se mais alinhada à segunda fase dos modelos de da ABPMP 
(2009) e Morais et al. (2014), e à terceira fase do modelo de Bernardo, Galina e Pádua (2017) que, em todos esses, se denomina fase de "Análise".

O modelo de Baldam (2008) não apresenta uma fase exclusiva que englobe esses pontos, porém, dentro da sua fase inicial, está inserida a preparação da visão global de processos, definição de planos de ação para implantação e seleção e priorização dos processos. Já no modelo de Scheer e Brabänder (2013) não foi identificada nenhuma fase que tratasse desses fatores.

A fase seguinte a ser analisada é semelhante nos seis modelos: Baldam (2008) a denomina de modelagem e otimização dos processos, Scheer e Brabänder (2013) chamam de desenho, e a ABPMP (2009), Morais et al. (2014) e Bernardo, Galina e Pádua (2017) denominam desenho e modelagem.

Em Dumas et al. (2013), as características desta etapa são divididas em 3 fases: descobrimento, análise e redesenho do processo. Observa-se que todas estas fases tratam da necessidade de desenhar os processos como parte de um ciclo de melhoria contínua.

Os modelos de Baldam (2008), Scheer e Brabänder (2013) e Dumas et al. (2013) destacam bem as etapas de desenho, análise e redesenho do processo otimizado, com o objetivo de melhor sua eficiência e alinhamento aos objetivos das organizações. Mesmo que apenas em Dumas et al. (2013) estas etapas estejam separadas em fases, os outros autores citados englobam com detalhes essas características em uma fase única. Todos estes autores destacam as etapas de modelagem "As Is" e "To Be".

A fase denominada "Execução" no modelo de Baldam e "Implantação" em todos os outros modelos analisados tem alto grau de convergência. Esta é a fase da efetiva realização das definições da fase de modelagem ou desenho em procedimentos e fluxos de trabalho. Alguns autores como Scheer e Brabänder (2013), Dumas et al. (2013) e Baldam (2008) comentam ainda sobre a necessidade da gestão de mudanças.

Além da implantação do processo, é preciso haver o controle do mesmo em operação, logo esta fase também está presente em todos os modelos analisados. Os autores concordam que esta etapa dá informações chaves sobre o comportamento dos processos. Nesta fase, são usadas diversas técnicas para manter os processos sob controle e mensurar a eficiência dos mesmos. 
Quadro 4- Semelhanças entre as fases dos modelos analisados

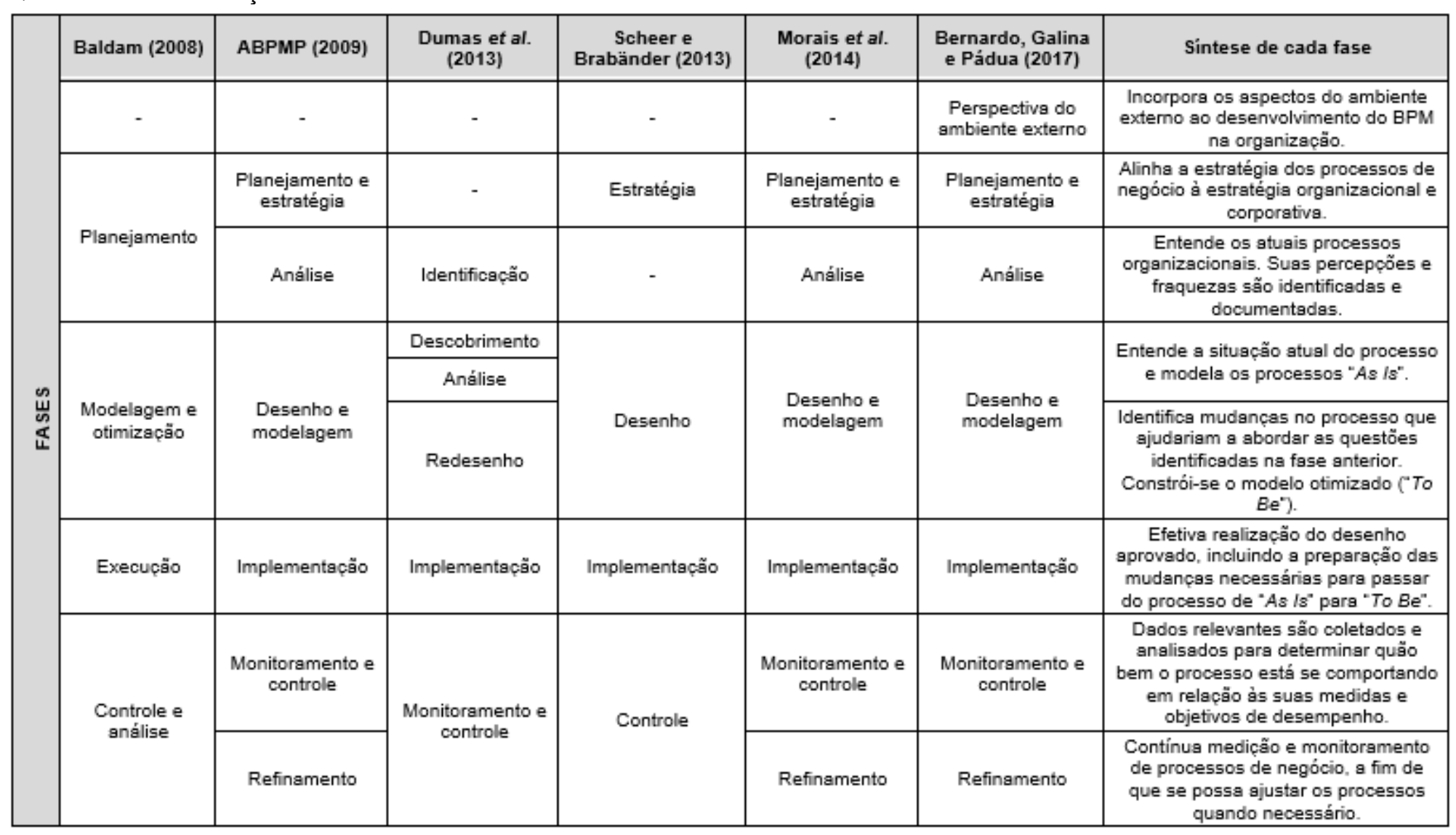

Fonte: Elaborado pelos autores (2017) 
Por fim, os modelos da ABPMP (2009), Morais et al. (2014) e Bernardo, Galina e Pádua (2017) ainda apresentam em seus modelos a fase de "Refinamento", que trata da contínua medição e monitoramento de processos de negócio. Apesar dos outros modelos não proporem uma fase específica para tal, identificou-se que as características dessa etapa estão presentes neles, incorporadas em sua última fase, uma vez que realimentação das informações que caracteriza um ciclo de melhoria contínua é apresentado em todos os modelos analisados.

De acordo com a análise das fases compreendidas por cada um dos seis modelos, bem como as suas peculiaridades, foi elaborado um quadro resumo (Quadro 4), onde estão listadas todas as fases identificadas e em quais modelos estas fases estão presentes. Com isso, foi possível relacionar todos os modelos e identificar as fases semelhantes entre os mesmos.

\section{DEFINIÇÃO DE ATRIBUTOS CHAVES AO BPM}

Procurou-se entender quais atributos devem estar associados aos modelos BPM para implementação de um eficiente gerenciamento de processos. Diversos autores pontuam aspectos que consideram vitais às iniciativas BPM (TRKMAN, 2010; WONG et al., 2013; WONG, 2014; BAI; SARKIS, 2013; BOER; MÜLLER; CATEN, 2015; ENSSLIN et al., 2017; NIEHAVES et al., 2010; NIEHAVES; HENSER, 201; ROSEMANN et al., 2006; VOM BROCKE, 2013; HAMMER, 2103). Também se destacam modelos de maturidade como Fischer (2004); Rosemann et al. (2006)

Foram então selecionados sete atributos que tiveram sua importância respaldada por diversos autores e que são descritos a seguir:

\section{A) Alinhamento com a estratégia}

O alinhamento com as estratégias da organização é fundamental para o sucesso das iniciativas BPM (BAI; SARKIS, 2013; BOER; MÜLLER; CATEN, 2015; TRKMAN 2010; ENSSLIN et al., 2017 ROSEMANN et al., 2006; FISCHER, 2004). Bai e Sarkis (2013) e Boer, Müller e Caten (2015) argumentam que os processos devem ser projetados, executados, gerenciados e medido de acordo com as prioridades estratégicas. 
Segundo Ensslin et al., (2017) o alinhamento entre os processos de negócios e a estratégia organizacional é encontrado na adoção de práticas e métodos que visem a melhoria contínua em processos de negócios. Assim, é possível ver a relevância da associação e o alinhamento necessário entre a estratégia organizacional e o cumprimento dos processos de negócios, caracterizando a gestão desses processos como meio de alcançar uma direção estratégica, que se estabelece como um fator de sucesso crítico (ENSSLIN et al., 2017).

\section{B) Relação com o ambiente externo}

Além dos aspectos internos da organização, os fatores externos também se fazem fundamentais para o sucesso das iniciativas BPM (WONG et al., 2013; TRKMAN 2010; WONG, 2014; NIEHAVES et al., 2010; NIEHAVES; HENSER, 2011). No entanto, Wong (2014) comenta que até recentemente, poucos trabalhos consideraram como a existência de fatores externos à implementação do BPM podem afetar o desempenho.

Wong et al. (2013) sugere que o ambiente seja um bom ponto de partida para o framework BPM, uma vez que a organização é um sistema aberto que deve interagir com seu meio para sobreviver e desenvolver. Portanto, é imperativo projetar todos os processos para permitir uma interface entre o sistema e seu ambiente. Niehaves e Henser (2011) observaram que os atores de fora da organização são fatores críticos de sucesso em mudar o BPM. Logo o meio ambiente é uma força motriz importante para influenciar a estratégia e estrutura na organização (WONG et al., 2013).

\section{C) Alinhamento com recursos e capacidades da organização}

Dentro da pesquisa sobre BPM começou a ser incorporado o desenvolvimento de capacidades e competências necessárias para o gerenciamento de processos. (NIEHAVES; HENSER, 2011; NIEHAVES et al., 2010; BERNARDO; GALINA; PÁDUA, 2017)

As capacidades que foram estudadas na literatura sobre estratégia, estendendo-se à visão baseada em recursos (BARNEY, 1995), evoluíram através de conceitos relacionados com as capacidades dinâmicas (DCs) onde se destacam o trabalho de Teece et al (1997). As DCs permitem às organizações integrar, construir 
e reconfigure as competências internas e externas para dar suporte em ambientes em rápida mudança (TEECE et al., 1997).

Assim, o sucesso das iniciativas de BPM é influenciado pelas DC, uma vez que estas contribuem facilitando a adaptação da organização em resposta para o dinamismo do ambiente externo (NIEHAVES; HENSER, 2011; NIEHAVES et al., 2010).

\section{D) Atividades e ferramentas necessárias em cada fase}

Autores como Boer, Müller e Caten (2015) e Rosemann et al. (2006) destacam a importância de um conjunto de ferramentas e técnicas que suportam gerenciamento de processos, facilitando a modelagem, análise e melhoria de processos.

\section{E) Cultura e pessoal}

A cultura organizacional incorpora valores e crenças coletivas que transformam a empresa para o gerenciamento de processos. Logo a mesma cria um ambiente que complementa as várias iniciativas de BPM. (BAI; SARKIS, 2013; ROSEMANN; VOM BROCKE 2013).

As pessoas são consideradas um elemento chave no BPM (BOER; MÜLLER; CATEN 2015; ROSEMANN; VOM BROCKE, 2013; WONG, 2014; FISCHER, 2004). São elas que aprimoram e aplicam continuamente seus conhecimentos e habilidades para executar e melhorar os processos (ROSEMANN; VOM BROCKE, 2013). Logo a necessidade de capacitar os funcionários para o gerenciamento dos processos fundamentais, alocação de recursos e encorajamento para tomada de decisões essenciais para resolução de problemas e melhorias de processos. (WONG et al., 2013). Wong (2014) ainda argumenta sobre o apoio da gestão de alto nível e o realinhamento do poder, conhecimento e informação para níveis mais baixos na organização, que podem resultar em aumento de produtividade, competitividade e desempenho.

\section{F) Tecnologia da informação}

A tecnologia da informação (TI) desempenha um papel central e papel importante em quase todos os projetos de BPM (BAI; SARKIS, 2013; FISCHER, 2004) A mesma tem sido um importante facilitador para gerenciar processos de negócios 
(WONG et al., 2013). A TI dá suporte a modelagem, execução e controle dos processos (BOER; MÜLLER; CATEN 2015; ROSEMANN et al., 2006). Uma vez que existem diversos softwares e sistemas relacionados ao BPM, como a arquitetura orientada a serviços (SOA), os sistemas de gerenciamento de processos (BPMS) dentre outros que auxiliam os esforços BPM e são suportados pela TI.

A TI é fundamental para reestruturação de processos que pode redefinir os limites dos mercados, o escopo do negócio e fornece um conjunto de armas competitivas, além disso facilita a integração de funções empresariais em todos os níveis de uma organização (WONG, 2014).

\section{G) Realimentação}

Por fim, a fase de realimentação dos modelos se faz fundamental para que se consiga a melhoria continua no gerenciamento dos processos. Como destaca ABPMP (2009) o BPM implica em um compromisso organizacional permanente e contínuo para gerenciar os processos da organização. Logo a presença dessa trata da contínua medição e monitoramento de processos de negócio, para que seja fornecido informações necessárias para ajustes, correções e melhorias (ABPM, 20019; DUMAS et al., 2013)

\section{ANÁLISE CRÍTICA DO ALINHAMENTO DOS MODELOS COM OS ATRIBUTOS}

O modelo de Bernardo, Galina e Pádua (2017) é o único que dedica uma fase exclusiva para os aspectos relacionados ao ambiente externo, porém o alinhamento para ele também é comentado no modelo de Baldam (2008), Scheer e Brabänder (2013) e da ABPMP (2009). O alinhamento com a estratégia é incorporado fortemente no modelo de Morais et al. (2014), Bernardo (2017) e Scheer e Brabänder (2013). Também é percebido, em menor grau, no modelo da ABPMP (2009) e em Baldam (2008). No modelo de Dumas et al. (2013) esse aspecto não foi identificado.

O alinhamento com capacidades e recursos da organização é identificado apenas no modelo de Bernardo, Galina e Pádua (2017). Quanto às atividades e ferramentas necessárias, foi observado que o modelo de Baldam (2008) dá mais atenção a este aspecto, uma vez que os detalha na maioria de suas fases, enquanto nos outros modelos este aspecto tem menor intensidade. 
Os aspectos culturais e o alinhamento entre os processos e as pessoas envolvidas são aspectos convergentes nos modelos. Bernardo, Galina e Pádua (2017) falam do engajamento de liderança, estabelecimento de comunicação, valores e culturas e governança eficiente. Já Baldam (2008) comenta sobre a interação com os envolvidos, atividades de colaboração, treinamentos, entre outros. Morais et al. (2014) também falam da governança de processos alinhada as pessoas, enquanto Dumas et al. (2013) e Scheer e Brabänder (2013) destacam a comunicação e o treinamento, e a ABPMP (2009) destaca a identificação dos papéis e responsabilidades estratégicas.

As tecnologias de informação estão presentes em todos os modelos analisados, e foi identificado maior ênfase no modelo de Dumas et al. (2013). O autor ressalta que a $\mathrm{TI}$ é um instrumento fundamental para melhorar os processos de negócios. No entanto, para alcançar a máxima eficácia, os engenheiros de sistemas precisam estar cientes de que a tecnologia é apenas um instrumento para gerenciar e executar processos.

Por fim, a realimentação do modelo, formando um ciclo de melhoria contínua, também é observado em todos os modelos, e nos modelos da ABPMP (2009), Morais et al. (2014) e Bernardo, Galina e Pádua (2017) existe uma fase dedicada a este aspecto (o refinamento).

O Quadro 5 apresenta estes sete fatores de análise, além da uma avaliação do grau no qual estão presentes em cada um dos modelos abordados.

Quadro 5 - Grau de presença dos atributos analisados

\begin{tabular}{|c|c|c|c|c|c|c|}
\hline \multirow{2}{*}{ Fatores analisados } & \multicolumn{6}{|c|}{ Modelo } \\
\hline & 1 & 2 & 3 & 4 & 5 & 6 \\
\hline Relação com o ambiente externo & $\bullet$ & $\bullet$ & 0 & $\bullet$ & • & $\bullet$ \\
\hline Alinhamento com a estratégia & $\bullet$ & - & 0 & $\bullet$ & $\bullet$ & $\bullet$ \\
\hline Alinhamento com capacidades e recursos da organização & O & O & 0 & O & O & $\bullet$ \\
\hline Atividades e ferramentas necessárias em cada fase & $\bullet$ & $\bullet$ & $\mathbf{0}$ & - & • & • \\
\hline Cultura e pessoal & $\bullet$ & $\bullet$ & $\bullet$ & $\bullet$ & $\bullet$ & • \\
\hline Tecnologia da informação & - & 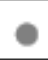 & $\bullet$ & 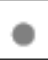 & - & - \\
\hline Realimentação & ○ & - & - & $\bullet$ & $\bullet$ & • \\
\hline \multicolumn{7}{|c|}{$\begin{array}{l}\text { Legenda: (1) Baldam (2008), (2) ABPMP (2009), (3) Dumas et al. (2013), (4) Scheer e Brabänder } \\
\text { (2013), (5) Morais et al. (2014), (6) Bernardo, Galina e Pádua (2017) }\end{array}$} \\
\hline
\end{tabular}

Fonte: Elaborado pelos autores (2017) 
Nota-se que o modelo de Bernardo, Galina e Pádua (2017) possui presença forte em cinco dos sete fatores de análise, e presença moderada em dois fatores. Os modelos de Scheer e Brabänder (2013) e Morais et al. (2014) têm fatores muito semelhantes, assim como os modelos de Baldam (2008) e da ABPMP (2009). modelo de Dumas et al. (2013) é que tem menor presença dos fatores analisados.

\section{CONCLUSÕES}

Este estudo indicou uma convergência moderada dos modelos BPM analisados, que é mais forte nas fases intermediárias (desenho, implementação, controle e monitoramento).

Com relação alinhamento com atributos chaves ao BPM (quadro 5), houve destaque para o modelo de Bernardo, Galina e Pádua (2017) que é o único que apresenta forte relação com o ambiente externo e alinhamento com capacidades e recursos da organização, sendo este fator ausente em todos os outros modelos. Quanto ao modelo de Dumas et al. (2013) foi identificado a ausência do alinhamento com o ambiente externo e com a estratégia da organização, o que deve dificultar que a gestão por processos atenda às necessidades da organização. Os demais fatores foram identificados em todos os modelos, a maioria em grau moderado.

Uma vez que o sucesso das iniciativas de BPM é influenciado pelas capacidades, que contribuem facilitando a adaptação da organização em resposta para o dinamismo do ambiente externo (NIEHAVES; HENSER, 2011; NIEHAVES et al., 2010), o alinhamento do modelo de Bernardo, Galina e Pádua (2017), com capacidades e recursos da organização, bem como com o ambiente externo, faz dele o mais completo e, portanto, mais propício dentre estes, para que as organizações possam responder o mais rapidamente possível às mudanças de mercado enfrentadas.

Este trabalho contribuiu academicamente por apresentar uma síntese de modelos BPM com diferenças e peculiaridades, bem como pontos fortes e fracos o que pode ser útil para pesquisadores ao buscarem estudar sobre diferentes modelos de gerenciamento de processos. Este trabalho também apresenta contribuição prática pois pode ajudar profissionais a adotar modelos e promover o BPM. 
Como limitações, pode-se considerar a subjetividade das análises que foram feitas a partir das informações que continham nos trabalhos cujo foram desenvolvidos os modelos. E também pode-se considerar uma limitação o fato que este trabalho analisou modelos tradicionais de ciclo BPM. Sabendo-se que existem na literatura os modelos ágeis de BPM (o tópico 9 comenta sobre eles) pode-se utilizar a metodologia dessa pesquisa para estudar estes modelos ágeis de BPM, bem como estudar em profundidade as relações entre estas duas abordagens.

Contudo ressalta-se a contribuição deste trabalho, pela importância de ainda se estudar modelos tradicionais, visto que como comentado neste trabalho existem vantagens e desvantagens em cada uma dessas abordagens e casos mais oportunos para que estes modelos sejam utilizados, desse modo continuam a existir novas literaturas desenvolvendo modelos tracionais de BPM, havendo assim oportunidades de pesquisa. Outra oportunidade de pesquisas futuras é levantar outros atributos, ou diferentes fatores de análise e analisar modelos BPM sobre outros enfoques, uma vez que essa área de estudo é ampla e ainda há aspectos que podem explorados.

\section{REFERÊNCIAS}

ABPMP. Guia para o gerenciamento de processos de negócio: corpo comum de conhecimento (BPM CBOK), versão 2.0. ABPMP Brasil, 2009.

BAI, C.; SARKIS, J. A grey-based DEMATEL model for evaluating business process management critical success factors. International Journal Of Production Economics, v. 146, n. 1, p.281-292, nov. 2013. https://doi.org/10.1016/i.jpe.2013.07.011

BALDAM, R. Gerenciamento de processos de negócios no setor siderúrgico: proposta de estrutura para implantação. 2008. 251f. Tese (Doutorado em Engenharia de Produção) Universidade federal do Rio de Janeiro, Rio de Janeiro, 2008.

BARNEY, J.B. Looking inside form competitive advantage. The Academy of Management Executive, v. 9, n. 4, p. 49-61, 1995. https://doi.org/10.5465/AME.1995.9512032192

BERNARDO, R.; GALINA, S. V. R.; PÁDUA, S. I. D. The BPM lifecycle: How to incorporate a view external to the organization through dynamic capability. Business Process

Management Journal, v. 23, n. 1, p. 155-175, 2017. http://dx.doi.org/10.1108/BPMJ-12$\underline{2015-0175}$

BIDER, I.; BELLINGER, G.; PERJONS, E. Modeling an agile enterprise: Reconciling systems and process thinking. Lecture Notes in Business Information Processing, v. 92, p. 238-252, 2011. https://doi.org/10.1007/978-3-642-24849-8 18 
BIDER, I.; JALALI, A. Agile business process development: why, how and whenapplying Nonaka's theory of knowledge transformation to business process development. $\mathrm{v}$. 14, p. 693-731, 2016. https://doi.org/10.1007/s10257-014-0256-1

BOER, F. G.; MÜLLER, C. J.; CATEN, C. S. Assessment model for organizational business process maturity with a focus on BPM governance practices. Business Process Management Journal, v. 21, n. 4, p.908-927, 6 jul. 2015. http://dx.doi.org/10.1108/BPMJ11-2014-0109

BROCKE, J. V.; ROSEMANN, M. Manual de BPM: gestão de processos de negócio. Porto Alegre: Bookman, 2013.

BURMEISTER, B. et al. Agile Processes Through Goal- and Context-Oriented Business Process Modeling. Business Process, v. 4103, p. 217-228, 2006.

https://doi.org/10.1007/11837862 22

DE SORDI, J. O. Gestão por processos: uma abordagem da moderna administração. São Paulo: Saraiva, 2008.

DUMAS, M. et al. Fundamentals of Business Process Management. Berlim: Springer, 2013.

ENSSLIN, L.; et al. BPM governance: a literature analysis of performance evaluation.

Business Process Management Journal, v. 23, n. 1, pp. 71-86, 2017. https://doi.org/10.1108/BPMJ-11-2015-0159

FISCHER, D.M. The business process maturity model: a practical approach for identifying opportunities for optimization. Business Process Trends, 2004.

HAMMER, M. O que é Gestão de Processos de Negócio? In: BROCKE, J.V.; ROSEMANN, M. (Eds), Manual de BPM: Gestão de processos de negócio, Bookman, Porto Alegre, 2013.

KLUSKA, R. A.; LIMA, E. P.; COSTA, S. E. G. Uma proposta de estrutura e utilização do Gerenciamento de Processos de Negócio (BPM). Revista Produção Online, v. 15, n. 3, p. 886-913, 2015. https://doi.org/10.14488/1676-1901.v15i3.1867

MARTINS, P. V.; ZACARIAS, M. An Agile Business Process Improvement Methodology. Procedia Computer Science, v. 121, p. 129-136, 2017.

https://doi.org/10.1016/j.procs.2017.11.018

MCCORMACK, K. et al. A global investigation of key turning points in business process maturity. Business Process Management Journal, v. 15, n. 5, p.792-815, 11 set. 2009. https://doi.org/10.1108/14637150910987946

MORAIS, R. M. et al. An analysis of BPM lifecycles: from a literature review to a framework proposal. Business Process Management Journal, v. 20, n. 3, p. 412-432,

2014. https://doi.org/10.1108/BPMJ-03-2013-0035

NIEHAVES, B.; HENSER, J. Boundary spanning practices in BPM: a dynamic capability perspective. Proceedings of the 17th Americas Conference on Information Systems, Detroit, MI, August 4-7, 2011.

NIEHAVES, B., PLATTFAUT, R.; BECKER, J. Does your business process management (still) fit the market? - a dynamic capability perspective on BPM strategy development. 
Proceedings of the 17th Americas Conference on Information Systems, Detroit, MI, August 12-15, 2010.

OLIVEIRA, D. P. R. Administração de processos: conceitos, metodologia e prática. 5. ed. São Paulo: Atlas, 2013.

PAIM, R. et al. Gestão de processos: pensar, agir e aprender. Porto Alegre: Bookman, 2009.

ROSEMANN, M; DE BRUIN, T; POWER, B. A model to measure business process management maturity and improve performance. In: JESTON, J; NELIS, J. (eds) Business process management. ButterworthHeinemann, Oxford, 2006.

ROSEMANN, M.; VOM BROCKE, J. Os seis elementos centrais da gestão de processos de Negócio, in: BROCKE, J.V.; ROSEMANN, M. (Eds), Manual de BPM: gestão de processos de negócio, Bookman, Porto Alegre, 2013.

SCHMIEDEL, T.; VOM BROCKE, J.; RECKER, J. Development and validation of an instrument to measure organizational cultures' support of Business Process Management. Information \& Management, v. 51, p. 43-56, 2014. https://doi.org/10.1016/j.im.2013.08.005

SCHEER, A.-W.; BRABÄNDER, E. O Processo de Gestão de Processos de Negócio. In: BROCKE, J. V.; ROSEMANN, M. (Eds.). Manual de BPM: Gestão de processos de negócio (pp. 279-306). Porto Alegre: Bookman, 2013.

TEECE, D. J. Explicating dynamic capabilities: the nature and microfoundations of (sustainable) enterprise performance. Strategic Management Journal, v. 28, n. 13, p. 13191350, 2007. https://doi.org/10.1002/smj.640

TEECE, D. J., PISANO, G., SHUEN, A. Dynamic capabilities and strategic management. Strategic Management Journal, v. 18, n. 7, p. 509-533, 1997. https://doi.org/10.1002/(SICl)1097-0266(199708)18:73.0.CO;2-Z

TEGNER, M. G. et al. Lean Office e BPM: proposição e aplicação de método para a redução de desperdícios em áreas administrativas. Revista Produção Online, v. 16, n. 3, p. 10071032, 2016. https://doi.org/10.14488/1676-1901.v16i3.2308

THIEMICH, C.; PUHLMANN, F. An agile BPM project methodology. Lecture Notes in Computer Science (including subseries Lecture Notes in Artificial Intelligence and Lecture Notes in Bioinformatics), v. 8094 LNCS, p. 291-306, 2013. https://doi.org/10.1007/978-3-642-40176-3 25

TRKMAN, Peter. The critical success factors of business process management. International Journal Of Information Management, v. 30, n. 2, p.125-134, abr. 2010. https://doi.org/10.1016/j.ijinfomgt.2009.07.003

VALLE, R.; COSTA, M. M. Gerenciar os processos para agregar valor à organização. In: VALLE, R.; OLIVEIRA, S. B. B. J. Descrevendo os processos de sua organização. São Paulo: Atlas, 2013, p. 28-36.

WEBER, B. et al. Towards a Framework for the Agile Mining of Business Processes. Business Process Management Workshops, v. 3812, n. September, p. 191-202, 2006. 
WONG, W. P. Business-process management: a proposed framework for future research. Total Quality Management \& Business Excellence, v. 24, n. 5-6, p.719-732, jun. 2013. https://doi.org/10.1080/14783363.2013.776773

WONG, W. P. et al. The impact of external environmental on business process management and organizational performance. Service Business, v. 8, n. 4, p.559-586, 17 set. 2013. https://doi.org/10.1007/s11628-013-0207-9

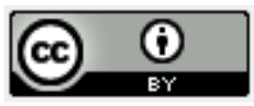

Artigo recebido em 04/06/2017 e aceito para publicação em 09/07/2018

DOI: http://dx.doi.org/10.14488/1676-1901.v18i3.2905 